\title{
Implementasi Algoritma Rot Dan Subtitusional Block Cipher Dalam Mengamankan Data
}

\author{
Ayu Pratiwi \\ STMIK Budi Darma Medan, Sumatera Utara, Indonesia \\ Jl. Sisingamangaraja No. 338 Simpang Limun Medan \\ ABSTRACT \\ http://stmik-budidarma.ac.id // Email : ayupratiwi455@gmail.com \\ The security and confidentiality of data is one of the most important aspects in the \\ information system at this time. Caused by the rapid development of science and \\ technology that allows the emergence of new techniques, which are misused by \\ certain parties that threaten the security of information systems. In general, the data \\ are categorized into two, namely confidential data and data that is not confidential. \\ Data that is not confidential is usually not too much attention. What really needs to be \\ considered is confidential data, where every information contained in it will be very \\ valuable for those who need it because the data can be easily duplicated. \\ The ROT-n algorithm is one simple encryption algorithm that uses alphabetical shifts \\ as much as $\mathrm{n}$ to convert plain text into cipher text, whereas Block ciphers work by \\ processing data in blocks, where several characters / data are combined into one \\ block. Each one block process produces one block output as well.
}

Keywords: Implementation, ROT-Algorithm and Block Cipher Substitutional.

\section{PENDAHULUAN}

Keamanan dan kerahasiaan data merupakan salah satu aspek yang sangat penting dalam sistem informasi pada saat ini. Disebabkan pesatnya perkembangan ilmu pengetahuan dan teknologi yang memungkinkan munculnya teknik-teknik baru, yang disalah gunakan oleh pihak-pihak tertentu yang mengancam keamanan dari sistem informasi tersebut. Jatuhnya informasi ke tangan pihak lain dapat menimbulkan kerugian bagi pemilik informasi. Secara umum data dikategorikan menjadi dua, yaitu data yang bersifat rahasia dan data yang tidak bersifat rahasia.

Enkripsi merupakan suatu proses pengubahan pesan asli menjadi karakter yang tidak dapat dibaca. Ada beberapa algoritma enkripsi yang biasa digunakan seperti Block Cipher, Stream Cipher, Data Encryption Standard (DES), Triple DES, Advanced Encryption Standard (AES), dan sebagainya. Dimana setiap algoritma memiliki karakteristik tersendiri. Sedangkan proses pengubahan kembali hasil enkripsi menjadi pesan asli dinamakan dekripsi. Untuk merahasiakan data yang sangat penting maka digunakanlah metode kriptografi yang akan mengenkripsi dan deskripsikan data ${ }^{[2]}$.

Dari beberapa metode yang ada dalam mengamankan data digunakanlah Algoritma ROT dan Subtitusional Block Chiper. Algoritma ROT-n merupakan salah satu algoritma enskripsi sederhana yang menggunakan pergeseran abjad-abjad sebanyak $\mathbf{n}$ untuk mengubah plain text menjadi cipher text. Sedangkan Block cipher bekerja dengan memproses data secara blok, dimana beberapa karakter / data digabungkan menjadi satu blok. Setiap proses satu blok menghasilkan keluaran satu blok juga. metode ini diimplementasikan pada level binary digit (bit), sehingga pola proses enkripsi tidak dapat terbaca, serta proses enkripsi dan dekripsi memerlukan waktu yang singkat

Berdasarkan latar belakang pemilihan judul, maka yang menjadi permasalahan dalam penelitian ini, yaitu :

1. Bagaimana penerapan algoritma ROTn dan diteruskan dengan teknik blok pada proses penyandian data?

2. Bagaimana merancang aplikasi pengamanan data dengan Algoritma ROT dan Subtitusional Block Cipher dalam mengamankan data?

Manfaat dari penulisan penelitian ini adalah :

1. Mengetahui proses penyandian data dengan teknik subtitusi menggunakan Algoritma ROTn dan diteruskan dengan teknik blok .

2. Dapat digunakan untuk mengaman data.

3. Sebagai bahan perbandingan bagi penulis lain mengenai metode kriptografi yang telah ada pada saat ini.

4. Dapat memperkaya literature mengenai kriptografi khususnya algoritma ROT dan Cipher Block, sehingga nantinya dapat bermanfaat untuk menjaga keamanan data dan dapat diimplementasikan.

\section{LANDASAN TEORI}




\subsection{Implementasi}

Implementasi adalah tahapan penerapan atau tindakan yang diperlukan agar mencapai sukses dalam suatu penelitian. Oleh karenanya, tahapan ini bukan lagi sebagai wacana pemikiran atau ide lagi, tetapi sudah berada pada tahapan perilaku dan tindakan yang diperlukan dalam penelitian ${ }^{[5]}$

Menurut Van Horn dan Van Meter dalam buku terjemahan Wahab, Implementasi dapat diartikan sebagai tindakan-tindakan oleh individu publik dan swasta atau kelompok yang diarahkan pada prestasi tujuan yang ditetapkan dalam keputusan kebijakan sebelumnya. Jadi Implementasi dimaksudkan sebagai tindakan individu publik yang diarahkan pada tujuan serta ditetapkan dalam keputusan dan memastikan terlaksananya dan tercapainya suatu kebijakan serat memberikan hasil yang bersifat praktis terhadap sesama ${ }^{[8]}$.

\subsection{Kriptografi}

Kriptografi (cryptography) berasal dari Bahasa Yunani, terdiri dari dua suku kata yaitu "cryptos" artinya "secref" (rahasia), sedangkan "graphein" artinya "writing" (tulisan), Jadi, kriptografi berarti "secret writing" (tulisan rahasia). Kriptografi adalah ilmu yang mempelajari teknik-teknik matematika yang berhubungan dengan aspek keamanan informasi, seperti kerahasiaan, keadsahan data, integritas data, serta autentikasi data. Secara umum kriptografi adalah ilmu dan seni untuk menjaga kerahasiaan berita (bruce Schneier - Applied Criptography).

Selain definisi tersebut diatas, terdapat pula definisi yang dikemukakan didalam Kriptografi adalah ilmu yang mempelajari teknik-teknik matematika yang berhubungan dengan aspek keamanan informasi, seperti kerahasiaan, integritas data, serta otentikasi. [7].

Ada empat tujuan mendasar dari ilmu kriptografi ini yang juga merupakan aspek keamanan informasi yaitu ${ }^{[7]}$ :

1. Kerahasiaan, adalah layanan yang ditujukan untuk menjaga agar pesan tidak dapat dibaca oleh pihak-pihak yang tidak berhak

2. Integritas data, adalah layanan yang menjamin pesan masih asli/utuh atau belum pernah dimanipulasi selama pengiriman

3. Otentikasi, adalah layanan yang berhubungan dengan identifikasi, baik mengidentifikassi kebenaran pihak-pihak yang berkomunikassi (user authentication atau entity authentication) maupun mengidentifikasi kebenaran sumber pesan (origin authentication)

Nirpenyangkalan (non-repudiation), adalah layanan untuk mencegah entitas yang berkomunikasi melakukan penyangkalan, yaitu pengirim pesan menyangkal melakukan pengiriman atau penerima pesan menyangkal telah menerima pesan.

\subsection{Algoritma}

Algoritma adalah urutan langkah-langkah untuk memecahkan suatu masalah. Terdapat macam-macam definisi algoritma, berikut ini merupakan beberapa definisi lain dari algoritma, antara lain:

1. Algoritma adalah deretan langkahlangkah komputasi yang mentransformasikan data masukan menjadi data keluaran.

2. Algoritma adalah deretan intruksi yang jelas untuk memecahkan masalah, yaitu untuk memperileh keluaran yang diinginkan dari suatu masukan dalam jumlah waktu yang terbatas.

3. Prosedur komputasi yang terdefinisi dengan baik yang menggunakan beberapa nilai sebagai masukan dan menghasilkan beberapa nilai yang disebut keluaran. Jadi Algoritma adalah deretan langkah komputasi yang masukan menjadi keluaran (Rinaldi Munir, 2007: 4).

\subsection{Algoritma ROT}

ROT-n (rotate by $\mathbf{n}$ ) merupakan salah satu algoritma enskripsi sederhana yang menggunakan pergeseran abjad-abjad sebanyak $\mathbf{n}$ untuk mengubah plain text menjadi cipher text. Artinya jika pada ROT-13, abjad $\mathrm{A}$ diganti dengan $\mathrm{N}$ sedangkan abjad $\mathrm{B}$ diganti dengan $\mathrm{O}$ demikian seterusnya.Secara sederhana berikut penggunaan algoritma ROT-13:

ABCDEFGHIJKLMNOPQRSTUVWXYZabcd efghijklmnopqrstuvwxyz NOPQRSTUVWXYZABCDEFGHIJKLMnopq rstuvwxyzabcdefghijkIm

Dari uraian diatas jelas terlihat bahwa pada ROT-13 setiap abjad A akan diganti dengan abjad N, setiap abjad a akan diganti dengan abjad n. Demikian seterusnya.

Contoh:

KOMPUTER (plaintext)

XBZCHGRE (ciphertext, hasil enskripsi ROT-13)

BfDGLKvl (cipher text, hasil enskripsi ROT-17)

Algoritma ini pertama kali dikemukakan oleh Julius Caesar untuk melakukan 
komunikasi dengan para panglimanya. (http://elib.unikom.ac.id diakses tanggal,06April-2015,Jam-21.54-WIB).

\subsection{Algoritma Block Cipher}

Block Cipher adalah algoritma enkripsi yang akan membagi-bagi plaintext yang akan dikirimkan dengan ukuran tertentu (disebut blok) dengan panjang $t$, dan setiap blok dienkripsi dengan menggunakan kunci yang sama. Pada umumnya, block cipher memproses plaintext dengan blok yang relatif panjang lebih dari 64 bit, untuk mempersulit penggunaan pola-pola serangan yang ada untuk membongkar kunci.

Pada cipher blok, rangkaian bit-bit plainteks dibagi menjadi blok- blok bit dengan panjang sama, biasanya 64 bit (tapi adakalanya lebih). Algoritma enkripsi menghasilkan blok cipherteks yang berukuran sama dengan blok plainteks. Dengan blok cipher, blok plainteks yang sama akan dienkripsi menjadi blok cipherteks yang sama bila digunakan kunci yang sama pula. Ini berbeda dengan cipher aliran dimana bitbit plainteks yang sama akan dienkripsi menjadi bit-bit cipherteks yang berbeda setiap kali dienkripsi.

Misalkan blok plainteks (P) yang berukuran $m$ bit dinyatakan sebagai vector:

$$
P=\left(P_{1}, P_{2}, P_{3} \ldots . . . P_{m}\right)
$$

Yang dalam hal ini $P_{i}$ adalah 0 atau 1 untuk $\mathrm{i}=1,2, \ldots, \mathrm{n}$, dan blok chiperteks (C) adalah:

$\mathrm{C}=\left(\mathrm{c}_{1}, \mathrm{c}_{2, \ldots}, \ldots \mathrm{c}_{\mathrm{n}}\right)$

Yang dalam hal ini $c_{1}$ adalah 0 atau 1 untuk $i=1,2, \ldots, n$. Bila plainteks dibagi menjadi $\mathrm{m}$ buah blok, barisan blok - blok plainteks dinyatakan sebagai:

$$
\left(P_{1}, P_{2}, \ldots, P_{m}\right)
$$

Untuk setiap blok plainteks $P_{i}$ bit- bit penyusunannya dapat dinyatakan sebagai vektor:

$$
P_{i}=\left(P_{i 1}, P_{i 2, \ldots . .,} P_{i n}\right)
$$

Enskripsi dan dekripsi dengan kunci $\mathrm{K}$ dinyatakan berturut-turut dengan persamaan:

Dan

$$
E_{k}(P)=C \text { (enkripsi)...(1) }
$$

$$
D_{k}(C)=P(\text { dekripsi)... } 2 \text { ) }
$$

Fungsi $E$ haruslah fungsi yang bekoresponden satu ke satu, sehingga:

$$
\mathrm{E}^{-1}=\mathrm{D} \text {. }
$$

Algoritma blok chipper menggabungkan beberapa teknik kriptografi klasik dalam proses enkripsi.Dengan kata lain, chipper blok dapa diacu sebagai super enkripsi. Teknik kriptografi klasik yang digunakan adalah :

1. Subtitusi

Teknik ini menggani satu atau sekumpulan bit pada blok plainteks tanpa mengubah urutannya. Secara matemais, teknik subtitusi ini ditulis sebagai $C_{i}=E\left(p_{i}\right), i=$ $1,2, \ldots$ (urutan bit), Yang dalam hal ini $c_{i}$ adalah bit cipherteks, $p_{i}$ adalah bit plainteks, dan $f$ adalah fungsi subtitusi. Dalam praktek, EE dinyatakan sebagai fungsi matematis atau dapat merupakan tabel substitusi (S-box).

2. Transposisi atau permutasi

Teknik ini memindahkan posisi bit pada blok plainteks berdasarkan aturan tertentu. Secara matematis, teknik transposisi ini ditulis sebagai $C=P M$, Yang dalam hal ini $\mathrm{C}$ adalah blok chiperteks, $\mathrm{P}$ adalah blok plainteks, dan $\mathrm{M}$ adalah fungsi transposisi. Dalam praktek, $M$ dinyatakan sebagai tabel matriks atau matriks permutasi.

3. Ekspansi

Teknik ini memperbanyak jumlah bit pada blok plainteks berdasarkan aturan tertentu. Misalnya dari 32 bit menjadi 48 bit. Dalam praktek, aturan ekspansi dinyatakan dengan tabel.

4. Kompresi

Teknik ini kebalikan dar ekspansi, di mana jumlah bit pada blok plainteks diciutkan berdasarkan aturan tertentu. Dalam prakteknya, aturan kompresi dinyatakan dengan tabel.

Contoh block chipper: DES, 3DES, GOST, RC5, AES, Blowfish, IDEA, LOKI, RC2, FEAL, Lucifer, CAST, CRAB, SAFER, Twofish, Serpent, RC6, MARS, Camellia, 3WAY, MMB, SkipJack, dll. (Rinaldi Munir, 2006: 118).

\subsection{Data}

Data adalah catatan atas kumpulan fakta. Data merupakan bentuk jamak dari datum, berasal dari bahasa Latin yang berarti "sesuatu yang diberikan". Dalam penggunaan sehari-hari data berarti suatu pernyataan yang diterima secara apa adanya. Pernyataan ini adalah hasil pengukuran atau pengamatan suatu variabel yang bentuknya dapat berupa angka, kata-kata, atau citra. Dalam keilmuan (ilmiah), fakta dikumpulkan untuk menjadi data. Data kemudian diolah sehingga dapat diutarakan secara jelas dan tepat sehingga dapat dimengerti oleh orang lain yang tidak langsung mengalaminya sendiri, hal ini dinamakan deskripsi. Pemilahan banyak data sesuai dengan persamaan atau perbedaan yang dikandungnya dinamakan klasifikasi.

Menurut berbagai sumber lain, data dapat juga didefinisikan sebagai berikut ${ }^{[3]}$ :

1. Menurut kamus bahasa inggrisindonesia, data berasal dari kata datum yang berarti fakta. 
2. Dari sudut pandang bisnis, data bisnis adalah deskripsi organisasi tentang sesuatu (resources) dan kejadian (transactions) yang terjadi.

\section{PEMBAHASAN}

\subsection{Analisa}

Adapun analisa yang akan dibahas adalah: Analisa Enkripsi Algoritma ROT, Analisa Enkripsi Algoritma Block Cipher (CBC), Analisa Dekripsi Algoritma Block Cipher (CBC), Analisa Dekripsi Algoritma ROT

\subsubsection{Analisa Enkripsi Algoritma ROT}

ROT-n (rotate by $\mathbf{n}$ ) merupakan salah satu algoritma enskripsi sederhana yang menggunakan pergeseran abjad-abjad sebanyak $\mathbf{n}$ untuk mengubah plain text menjadi cipher text. Artinya jika pada ROT-13, abjad A diganti dengan $\mathrm{N}$ sedangkan abjad $\mathrm{B}$ diganti dengan $O$ demikian seterusnya.

ABCDEFGHIJKLMNOPQRSTUVWXYZabcd efghijklmnopqrstuvwxyz

NOPQRSTUVWXYZABCDEFGHIJKLMnopq rstuvwxyzabcdefghijklm

Proses Enkripsi :

Plainteks = BUDIDARMA

Cipherteks $=$ OHRVRNEZN (Hasil Enkripsi)

\subsubsection{Analisa Algoritma Enkripsi Block Cipher}

Block Cipher adalah algoritma enkripsi yang akan membagi-bagi plaintext yang akan dikirimkan dengan ukuran tertentu (disebut blok) dengan panjang $t$, dan setiap blok dienkripsi dengan menggunakan kunci yang sama. Pada umumnya, block cipher memproses plaintext dengan blok yang relatif panjang lebih dari 64 bit, untuk mempersulit penggunaan pola-pola serangan yang ada untuk membongkar kunci. Pada cipher blok, rangkaian bit-bit plainteks dibagi menjadi blok- blok bit dengan panjang sama, biasanya 64 bit (tapi adakalanya lebih). Algoritma enkripsi menghasilkan blok cipherteks yang pada kebanyakan sistem kriptografi simetri berukuran sama dengan blok plainteks. Dengan blok cipher, blok plainteks yang sama akan dienkripsi menjadi blok cipherteks yang sama bila digunakan kunci yang sama pula. Ini berbeda dengan cipher aliran dimana bitbit plainteks yang sama akan dienkripsi menjadi bit-bit cipherteks yang berbeda setiap kali dienkripsi. Dalam mode operasinya menggunakan Cipher Block Chaining (CBC). Cara Kerja Algoritma Cipher Block Chaining :

1. Setiap block Ciphertext bergantung tidak hanya pada block plaintextnya tapi pada seluruh block sebelumnya.
2. Hasil enkripsi block sebelumnya diumpan balik kedalam enkripsi block yang current

3. Enkripsi block pertama memerlukan block semu (Co) yang disebut IV (Intialization Vektor)

4. IV dapat diberikan oleh pengguna atau dibangkitkan secara acak oleh program.

\section{Proses Enkripsi :}

Tabel 1 Proses Enkripsi

\begin{tabular}{|l|l|l|l|}
\hline Char & Desimal & Hexa & Biner \\
\hline O & 79 & $4 \mathrm{~F}$ & 01001111 \\
\hline $\mathrm{H}$ & 72 & 48 & 01001000 \\
\hline $\mathrm{R}$ & 82 & 52 & 01010010 \\
\hline $\mathrm{V}$ & 86 & 56 & 01010110 \\
\hline $\mathrm{R}$ & 82 & 52 & 01010010 \\
\hline $\mathrm{N}$ & 78 & $4 \mathrm{E}$ & 01001110 \\
\hline $\mathrm{E}$ & 69 & 45 & 01000101 \\
\hline $\mathrm{Z}$ & 90 & $5 \mathrm{~A}$ & 01011010 \\
\hline $\mathrm{N}$ & 78 & $4 \mathrm{E}$ & 01001110 \\
\hline
\end{tabular}

Plainteks $=01001111,01001000$,

01010010, 01010110, 01010010, 01001110,

$\operatorname{KUNCl}(\mathrm{K})=01010000$ 01011010,01001110

Intialization vektor :

$\mathrm{W}\left(\mathrm{C}_{0}\right) \quad 010000011$

$\underline{01001111}, \underline{01001000}, \underline{01010010}, \underline{01010110}$, $\underline{01010010}, \underline{01011110}, \underline{01000101}$,

$\mathrm{P} 1_{\mathrm{P} 5}^{\mathrm{P} 2} \frac{\mathrm{P}^{\mathrm{P} 3}}{\mathrm{P} 7}{ }^{\mathrm{P} 4}$

$\underline{01011010}, \underline{01001110}$

$$
\text { P8 P9 }
$$

$\mathrm{C} 1=\mathrm{P} 1 \oplus \mathrm{C} 0$

$=01001111^{\oplus} 01000011$

$=00001100$

$=00001100 \oplus \mathrm{K}$

$=00011000 \oplus 01010000$

$=01011100=>10111000$

$\mathrm{C} 2=\mathrm{P} 2 \oplus \mathrm{C} 1$

$=01001000 \oplus \stackrel{10111001}{\longrightarrow}$

$=11110001$

$=11110001 \oplus \mathrm{K}$

$=11100011 \oplus 01010000$

$=10100001 \Rightarrow 01000011$

$\mathrm{C} 3=\mathrm{P} 3 \oplus \mathrm{C} 2 \quad \longrightarrow \mathrm{R}$

$=01010010 \oplus 01000011$

$=00010001$

$=00010001 \oplus \mathrm{K}$

$=00010001 \oplus 01010000$

$=01000001=>10000011$

$\mathrm{C} 4=\mathrm{P} 4 \oplus \mathrm{C} 3 \quad \longrightarrow \mathrm{V}$

$=01010110 \oplus 10000011$

$=11010101$

$=11010101 \oplus \mathrm{K}$

$=11010101 \oplus 01010000$ 
$=10000101=>00001011$

$\mathrm{C} 5=\mathrm{P} 5 \oplus \mathrm{C} 4 \quad \longrightarrow \mathrm{R}$
$=01010010 \oplus 00001011$
$=01010101$
$=01010101 \oplus \mathrm{K}$
$=01010101 \oplus 01010000$
$=00000101=00001010$
$\mathrm{C} 6=\mathrm{P} 6 \oplus \mathrm{C} 5$
$=01001110 \oplus 00001010$
$=01000101$
$=01000101 \oplus \mathrm{K}$
$=01000101 \oplus 01010000$
$=00010101$
$\mathrm{C} 7=\mathrm{P} 7 \oplus \mathrm{C} 6$

$=01011010 \oplus 00010101$

$=01001111$

$=01001111 \oplus \mathrm{K}$

$=01001111 \oplus 01010000$

$=00011111=>00111110$

$\mathrm{C} 8=\mathrm{P} 8 \oplus \mathrm{C} 7 \quad \longrightarrow \mathrm{Z}$

$=00111110 \oplus 00001100$

$=01110010$

$=01110010 \oplus \mathrm{K}$

$=01110010 \oplus 01010000$

$=00100010=>01001000$

$\mathrm{C} 9=\mathrm{P} 9 \oplus \mathrm{C} 8$

$=01000101 \oplus 00001100$

$=01001001$

$=01001001 \oplus \mathrm{K}$

$=01001001 \oplus 01010000$

$=00011001=>01001000$

Jadi Hasil Enkripsinya adalah :

10111000, 01000011, 10000011, 00001011 , 00001010, 00010101, 00111110, 01001000, 01001000

\subsubsection{Analisa Dekripsi Algoritma Block Cipher}

Dekripsi Algoritma Block Cipher merupakan salah satu algoritma dekripsi sederhana yang menggunakan mode operasi Cipher Block Chaining $(C B C)$ untuk mengembalikan cipher text menjadi plain text semula. Pada dekripsi block plainteks diperoleh dengan cara meng Xor kan IV dengan hasil dekripsi terhadap block Cipherteks pertama.

\section{Proses Dekripsi}

$C=10111000,01000011,10000011$, 00001011, 00001010, 00001010, 00001100,

$\begin{array}{llllll}\mathrm{C} 4 & \mathrm{C} 1 & \mathrm{C} 5 & \mathrm{C} 2 & \mathrm{C} 6 & \mathrm{C} 3\end{array}$

$=10111000 \oplus 01000011$

$=11111011$

$=11111011 \oplus \mathrm{K}$

$=11111011 \oplus 01010000$

$=10101011=>01001111$

$\mathrm{P} 2=\mathrm{C} 2 \oplus \mathrm{C} 1$

$=01000011$

$=10100000 \oplus 10111000$

$=00011000$

$=00011000 \oplus \mathrm{K}$

$=00011000 \oplus 01010000$

$=01001000$

$\mathrm{P} 3=\mathrm{C} 3 \oplus \mathrm{C} 2$

$=10000011$

$=00000111 \oplus 01000011$

$=01000010$

$=01000010 \oplus 01010000$

$=01010010$

$\mathrm{P} 4=\mathrm{C} 4 \oplus \mathrm{C} 3 \quad \longrightarrow$ ।

$=00001011$

$=10001010 \oplus 10001100$

$=00000110$

$=00000110 \oplus 01010000$

$=01010110$

$\mathrm{P} 5=\mathrm{C} 5 \oplus \mathrm{C} 4$

$=00001010$

$=00000101 \oplus 00001011$

$=00000010$

$=00000010 \oplus 01010000$

$=01010010$

$\mathrm{P} 6=\mathrm{C} 6 \oplus \mathrm{C} 5$

$=00010101$

$=00101010 \oplus 00001010$

$=00011110$

$=00011110 \oplus 01010000$

$=01001110$

$\mathrm{P} 7=\mathrm{C} 7 \oplus \mathrm{C} 6$

$=00111110$

$=00011111 \oplus 00010101$

$=00001010$

$=00001010 \oplus 01010000$

$=01011010$

$\mathrm{P} 8=\mathrm{C} 8 \oplus \mathrm{C} 7$

$=01001000$

$=00100100 \oplus 00111110$

$=00011110$

$=00011110 \oplus 01010000$

$=01001110$

$\mathrm{P} 9=\mathrm{C} 9 \oplus \mathrm{C} 8$
$=00010101$

$=00101010 \oplus 00001010$

$=00011110$

$=00011110 \oplus 01010000$ 


\section{$=01001110$}

Jadi, hasil dekripsinya adalah :

01000010, 01010101, 01000100, 01001001, 01000100, 01000001, 01010010, 01001101, 01000001 = BUDIDARMA

\subsubsection{Analisa Dekripsi Algoritma ROT}

Dekripsi Algoritma ROT merupakan salah satu algoritma dekripsi sederhana yang menggunakan pergeseran abjad-abjad sebanyak $\mathbf{n}$ untuk mengembalikan ciphertext menjadi plaintext semula. Artinya jika pada ROT-13, abjad $N$ diganti dengan $A$ sedangkan abjad $\mathrm{O}$ diganti dengan $\mathrm{B}$ demikian seterusnya.

NOPQRSTUVWXYZABCDEFGHIJKLMnopq rstuvwxyzabcdefghijklm

ABCDEFGHIJKLMNOPQRSTUVWXYZabcd efghijklmnopqrstuvwxyz

Proses Dekripsi :

NOPQRSTUVWXYZABCDEFGHIJKLM

ABCDEFGHIJKLMNOPQRSTUVWXYZ

Cipherteks $=$ OHRVRNEZN

Plainteks = BUDIDARMA ( Hasil Dekripsi)

Tampilan menu utama merupakan tampilan yang muncul setelah menjalankan program untuk pengamanan teks. Tampilan menu utama dapat dilihat pada gambar 1

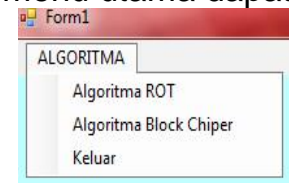

\section{Gambar 1 Form Menu Utama}

Pada gambar 1 diatas merupakan form menu utama yang berfungsi untuk menuju ke menu berikutnya sehingga pengguna bisa memilih menu untuk Algoritma ROT dan Algoritma Block Cipher.

Tampilan berikutnya dari menu adalah menu Algoritma ROT. Tampilan awal proses dapat dilihat pada gambar dibawah ini :

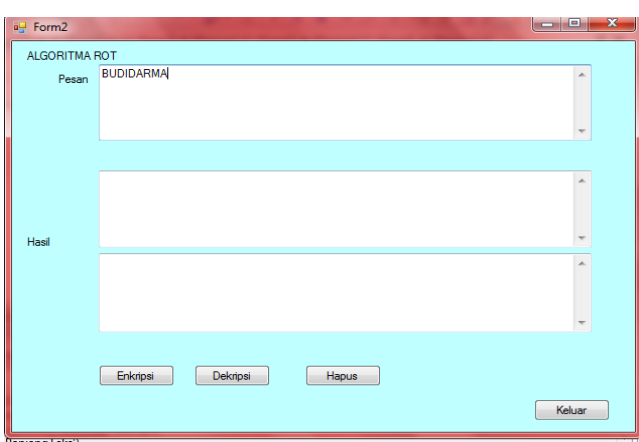

Gambar 2 Form Algoritma ROT

Pada gambar 2 diatas merupakan form Algoritma ROT yang berfungsi untuk proses enkripsi dan deskripsi dalam Algoritma ROT.

Tampilan berikutnya dari menu adalah menu Algoritma Block Cipher. Tampilan awal proses dapat dilihat pada gambar dibawah ini:

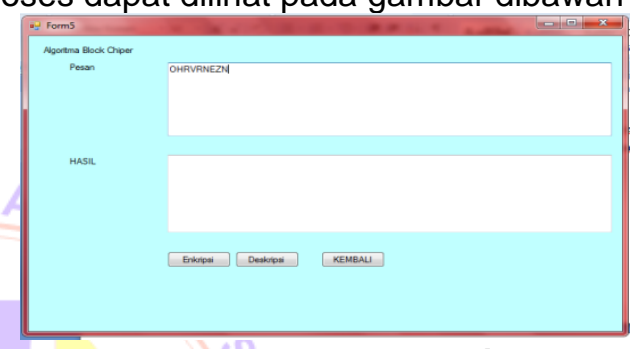

Gambar 3 Form Algoritma Block Cipher

Pada gambar 3 diatas merupakan form Algoritma Block Cipher yang berfungsi untuk proses enkripsi dan deskripsi.

Tampilan berikutnya dari menu adalah menu enkripsi algoritma ROT. Tampilan awal proses dapat dilihat pada gambar dibawah ini:

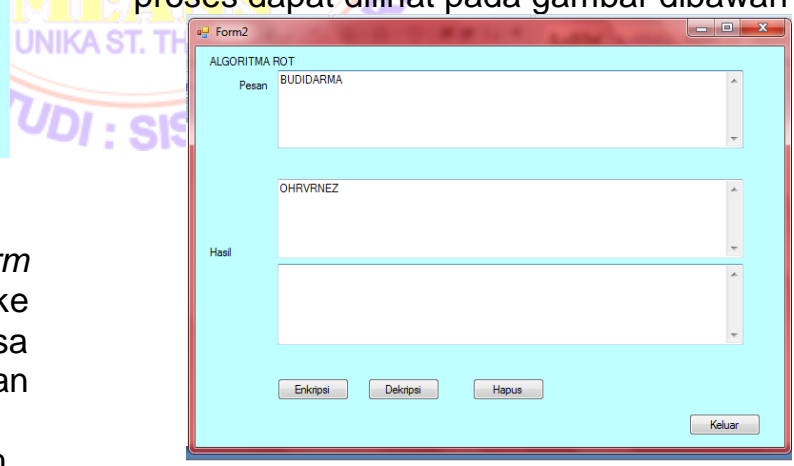

Gambar 4. Tampilan menu enkripsi Algoritma ROT

Tampilan berikutnya dari menu adalah menu Enkripsi algoritma Block Cipher. Tampilan awal proses dapat dilihat pada gambar dibawah ini : 


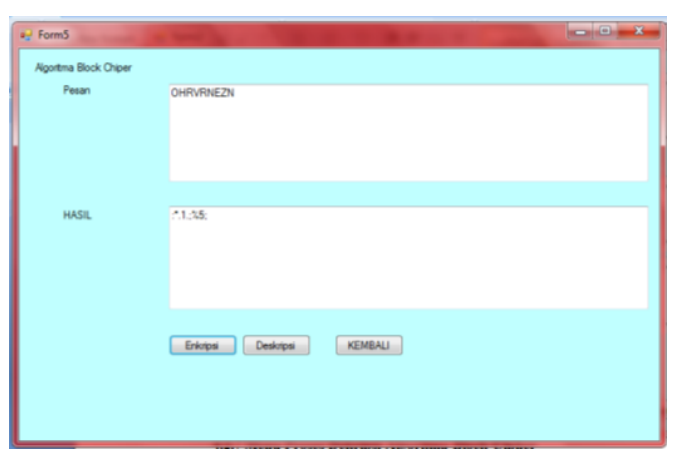

Gambar 5. Tampilan Menu Enkripsi Algoritma Block Cipher

Tampilan berikutnya dari menu adalah menu Dekripsi algoritma Block Cipher. Tampilan awal proses dapat dilihat pada gambar dibawah ini :

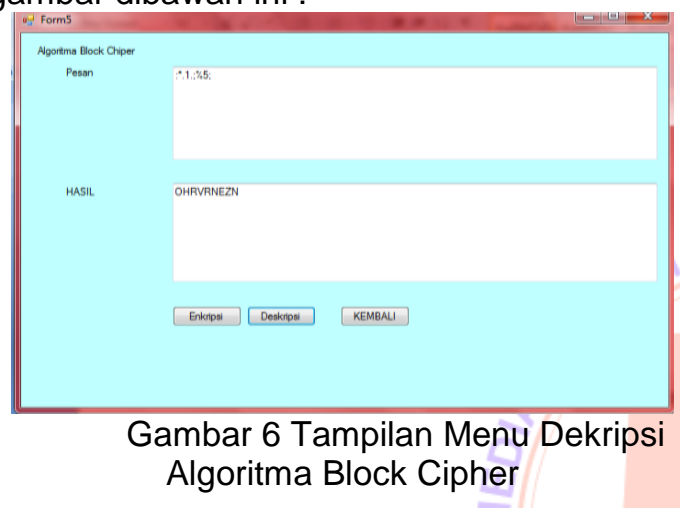

Tampilan berikutnya dari menu adalah menu Dekripsi algoritma ROT. Tampilan awal proses dapat dilihat pada gambar dibawah ini: panjang $t$, dan setiap blok dienkripsi dengan menggunakan kunci yang sama.

2. Program dapat dibuat dengan menggunakan bahasa pemograman visual basic 2008 dengan form enkripsi dan dekripsi.

\section{DAFTAR PUSTAKA}

1. Adi Nugroho, "Rekayasa Perangkat Lunak Berorientasi Objek Dengan Metode USDP", Penerbit Andi, Bandung, 2010

2. Dafid, "Kriptografi Kunci Simetri Dengan Menggunakan Algoritma Cryton", Vol. 2, No. 3, 2006

3. http://id.wikipedia.org/wiki/Data/.diakses ,21-04-2015

4. Kaidir, Abdul, "Pengenalan Algoritma Pendekatan Secara Visual Dan Interaktif Menggunakan Raptor", Penerbit Andi, Yogyakarta, 2013

5. Nurli Hairiah, "Analisa Dan Implementasi Algoritma Cipher Block Chaining Dalam Penyandian Teks ", Vol. 5, No. 1, 2015

6. Rifki Sadikin, "Kriptografi Untuk Keamanan Jaringan ", Penerbit Andi, Yogyakarta, 2012

7. Rinaldi Munir, "Kriptografi", Penerbit Informatika Bandung, Bandung, Edisi 1, 2006

8. Tata Sutabri, "Sistem Informasi Manajemen ", Penerbit Andi, Yogyakarta, 2005

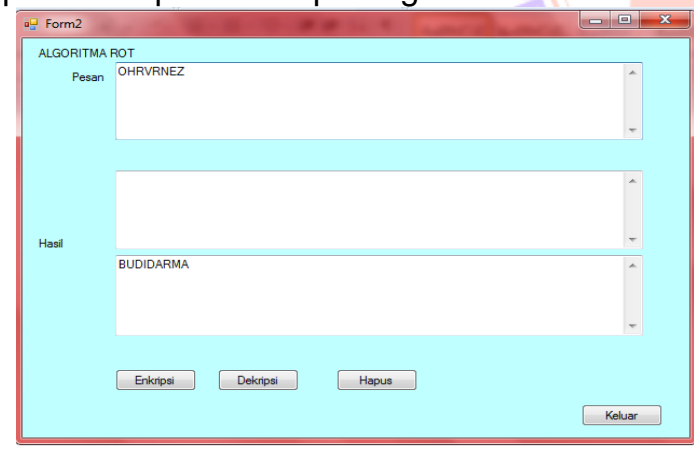

Gambar 7 Tampilan Menu Dekripsi Algoritma ROT

\section{KESIMPULAN}

Berdasarkan dari pembahasan skripsi tersebut maka penulis menarik kesimpulan sebagai berikut :

1. Algoritma ROT melakukan proses enskripsi sederhana yang menggunakan pergeseran abjad-abjad sebanyak $\mathbf{n}$ untuk mengubah plain text menjadi cipher text dan Algoritma Block Cipher melakukan proses enkripsi yang akan membagi-bagi plaintext yang akan dikirimkan dengan ukuran tertentu (disebut blok) dengan 